\title{
Del derecho al consumo al derecho a la ciudad: contradicciones y convergencias
}

Maria-Angélica Magrini. Universidade Federal de Uberlândia, Ituiutaba, Brasil. Igor Cataláo. Universidade Federal da Fronteira Sul, Chapecó, Brasil.

RESUMEN | En el contexto de la reestructuración productiva vinculada a procesos de reestructuración urbana en Brasil, segmentos de población de bajo poder adquisitivo han sido incorporados a la sociedad de consumo, con los consecuentes cambios en la producción de los espacios y en la sociabilidad urbana. En este contexto, el objetivo de este artículo es discutir el rol del consumo en la construcción del derecho a la ciudad, en tanto factor de alienación y desmovilización social, catalizador de la fragmentación socioespacial y, a la vez, potencial para la integración citadina, el establecimiento de identidades y la construcción de ciudadanía, dimensiones fundamentales a la reposición teórica y realización concreta del derecho a la ciudad. A partir de trabajos de campo y entrevistas con ciudadanos de ocho ciudades intermedias brasileñas, constatamos la necesidad de comprender el consumo por medio de la ciudadanía y la política, lo que posibilita la recualificación de la justicia espacial.

PALABRAS ClaVe | consumo, desigualdad social, fragmentación urbana.

ABSTRACT | Brazil has experienced the restructuring of the productive sector linked to processes of urban and city restructuring. In this context, population segments of lower acquisitive power have been recently incorporated to the society of consumption. This fact results in changes in the production of spaces and urban sociability. Therefore, the aim of this article is to discuss the dialectical contradiction inherent to the role of consumption in the construction of the right to the city. We consider that consumption must be understood as a matter of alienation, social demobilization and catalyzer of socio-spatial fragmentation as well as it is a potential element for city integration, the establishment of identities and citizenship construction. These are fundamental dimensions for theoretically repositioning and concretely achieving the right to city. The results obtained from fieldwork and interviews with city inhabitants of eight intermediate Brazilian cities allows us to observe the need to understand consumption through citizenship and politics, which is what allows the requalification of the spatial justice question.

KEYWORDS | consumption, social inequality, urban fragmentation.

Recibido el 21 de enero de 2016, aprobado el 1 de junio de 2016

E-mails: M.-A. Magrini, angelicaomagrini@gmail.com | I. Cataláo, igorcatalao@gmail.com 


\section{Introducción}

Vivimos, por primera vez en la historia brasileña, la inclusión de un amplio segmento de trabajadores en el mercado de consumo. Se trata de una inclusión retrasada en el contexto del desarrollo económico de Occidente, puesto que, según Osorio (2004), en los países centrales del sistema capitalista ese proceso ocurrió junto con el desarrollo industrial. Este es el elemento distintivo, en el ámbito de la división internacional del trabajo y de la geoeconomía política del capitalismo, entre lo que se podría identificar como centro y aquello posible de considerar como periferia, aun después de los cambios promovidos por la revolución tecnológica y por los procesos flexibles de producción y acumulación de este período postfordista.

Brasil ha visto un notorio desarrollo industrial vinculado a los procesos de desconcentración económica generados por la transnacionalización de las empresas, especialmente occidentales, que ha tenido lugar impulsado por una fragmentación técnica políticamente centralizada (Santos, 2004). Como resultado, el país ocupa hoy una posición de economía emergente y goza de notorio desarrollo económico. Mientras tanto, el desarrollo industrial, iniciado en los años 1950 y con auge contemporáneo para el sector agrotecnológico, no ha contemplado la inclusión de los trabajadores en el mercado de consumo, especialmente de aquellos que, desde los años 1960, han pasado a concentrarse en las aglomeraciones metropolitanas industriales. Vale decir, la industria brasileña, a diferencia de lo ocurrido en países como Inglaterra, Francia y Japón primero, y Corea del Sur y Australia después, se ha desarrollado para atender el mercado consumidor externo, con una inclusión precaria de su masa asalariada en la llamada "sociedad de consumo" (Baudrillard, 2009).

Aunque en Brasil las condiciones productivas y económicas para el acceso al consumo hayan sido creadas en función de las articulaciones de su economía al capitalismo mundializado, especialmente desde los años 1970, fue necesaria una decisión política para lograr avances significativos en el ámbito social. Tales avances han sido notorios solo en años recientes, principalmente en el período correspondiente a los dos mandatos del presidente Luiz Inácio Lula da Silva (2003-2010) y al primer mandato de la presidenta Dilma Rousseff (2011-2014), ambos del Partido de los Trabajadores (Рт). En ambos ha habido señales en cuanto a la disminución de la pobreza o la aparición de una controvertida "nueva clase media" (Bartelt, 2013), que representa, en realidad, una gran masa de trabajadores que ha tenido un acceso más amplio al consumo.

Según Vicente (2013),

No Brasil, mudanças socioeconômicas relativas às camadas populares vêm ocorrendo de modo mais significativo desde 2002. O Plano Real lançado em 1994 implantou uma política de estabilidade da moeda, que se somou a outros fatores como as políticas governamentais de incentivo à bancarização e do acesso fácil ao crédito, planos sociais de distribuição de renda e aumento gradativo dos salários. Esses fatores resultaram num aumento da participação da população na aquisição de bens de consumo e consequente aquecimento da economia no país. A partir daí 
as camadas emergentes passaram a ser vistas como "novos consumidores" tanto pelo governo como pelo mercado, mudando o desenho dos gráficos que representam as estatísticas oficiais e classificam as classes socioeconômicas no país. (p. 81)

Es, por lo tanto, en esa perspectiva que se desarrolla nuestra discusión. Es decir, nos ocupa el análisis de la relación entre el desarrollo en Brasil de una sociedad de consumo -que ha incorporado recientemente a los segmentos de más bajo poder adquisitivo- y las expresiones de ello en las formas de producción y apropiación de las ciudades, sobre todo en las que se han articulado de modo más intenso a las lógicas de restructuración económico-productiva y urbana. Este artículo tiene como objetivo central discutir la contradicción dialéctica inherente al consumo, ${ }^{1}$ en su calidad de ser a la vez modo de alienación y elemento potencial para la integración ciudadana, el establecimiento de identidades y la construcción de la ciudadanía, dimensiones fundamentales al reposicionamiento teórico y a la realización concreta del derecho a la ciudad. Se trata, por lo tanto, de una preocupación especialmente procesual, que busca contextualizar los conceptos relativos al desarrollo contemporáneo de la urbanización, para investigar caminos posibles a la realización de la "u-topía" (Lefebvre, 1999). Aunque sea un análisis científico, que sintetiza resultados de investigaciones, es, de igual manera, una posición política frente a la realidad, dado que -como ya decía Peet (1977) - nunca ha habido ciencia neutra. Recuperando, pues, sus preocupaciones, nos comprometemos con el cambio que conlleva la construcción del derecho a la ciudad.

Para desarrollar este análisis, es importante considerar la articulación de la economía brasileña a los procesos más amplios de acumulación capitalista vinculados a la reestructuración productiva en curso desde los años 1970, y a las resultantes reestructuraciones urbanas (Soja, 1993) y de las ciudades (Sposito, 2007). También debe examinarse la prevalencia del consumo como elemento que guía la sociabilidad urbana $^{2}$ contemporánea, entendido "en el sentido de gasto, compra y posesión de objetos visibles" (Baudrillard, 2009, p. 50) y como "sistema de comunicación y de

1 No vamos a insistir en la polarización, a veces moralizante, entre consumo (vinculado a los bienes necesarios) y consumismo (vinculado a los bienes superfluos), porque entendemos, acompańando la comprensión de Baudrillard (2009), que las cosas necesarias y superfluas no lo son a priori; o sea, que la propia necesidad es una producción social. Nos parece más adecuado trabajar con la idea de consumo como lenguaje, como sistema de comunicación y de intercambio que sostiene la sociedad contemporánea, es decir, la sociedad de consumo (Baudrillard, 2009; Lefebvre, 1971, 1999).

2 La sociabilidad se desarrolla en diferentes niveles, desde el más amplio, que fundamenta la existencia de las sociedades humanas, al más restringido de las microsociabilidades familiares, profesionales, de grupos, etcétera, que envuelven la necesidad de "estar junto". Tratamos la sociabilidad como expresión y condición de la vida colectiva en la ciudad, vinculada al "estímulo a la aglomeración urbana”, del que trata Soja (2008). Ello es lo que hace de la ciudad un éxito histórico de vida colectiva. Entretanto, entendemos que hay disyuntivas que se deben a las fuerzas existentes que cuestionan la vida colectiva e instauran lógicas de separación. Aunque siempre haya habido tensiones dialécticas entre la sociabilidad como agrupación y las disyuntivas que la cuestionan, se puede considerar que la ciudad hoy está marcada por la predominancia de tendencias disyuntivas que fragmentan espaciotemporalmente las prácticas de los ciudadanos. En la geografía, un debate interesante sobre la sociabilidad puede ser encontrado en Turra Neto (2008), quien se ha esforzado, apoyándose en Simmel (1983), Maffesoli (2004) y Giddens (2002), en difundir el debate sociológico respecto de la discusión sobre las expresiones espaciales de las relaciones sociales. 
intercambio, como código de signos continuamente emitidos y recibidos y reinventados como lenguaje (Baudrillard, 2009, p. 102, destacado en el original). ${ }^{3}$

En el ámbito de la reestructuración productiva mencionada, destacamos la división territorial del trabajo en Brasil con respecto a los roles que las ciudades desempeñan en el sistema urbano nacional, considerando sus articulaciones e interacciones espaciales desde la escala regional hasta la mundial. Consideramos especialmente las ciudades intermedias, cuyas funciones urbanas se han visto modificadas a partir de dos aspectos interdependientes: (i) la aparición o aumento de la acción de empresas de capital nacional y extranjero, sobre todo de los ramos industrial y comercial, lo que incide directamente en el sector de los servicios; y (ii) el acceso al consumo proporcionado primeramente por las políticas de inclusión económica-como la valoración del salario mínimo, la ampliación de la oferta de crédito y los programas redistributivos- y también por la implantación y ampliación de grandes superficies de consumo, como redes de franquías, hipermercados, tiendas de departamento, galerías y centros comerciales.

Considerando que Brasil es un país con desigualdades estructurales y que la urbanización es un proceso que se desarrolla, según Brenner y Schmid (2015), como expresión espacial del desarrollo desigual capitalista, nos cuestionamos sobre los impactos de los aspectos arriba mencionados en la vida y la configuración espacial urbanas. Al respecto, defendemos la tesis según la cual la fragmentación socioespacial se presenta como tendencia de la urbanización contemporánea.

El conjunto de reflexiones que se presenta en este artículo tiene su origen en resultados de investigaciones realizadas en las ciudades de Marília, Presidente Prudente, Ribeirão Preto, São Carlos y São José do Rio Preto, todas ellas del estado de São Paulo; en Londrina, estado de Paraná; ${ }^{4}$ y, de modo preliminar, en las ciudades de Chapecó, estado de Santa Catarina, e Ituiutaba, estado de Minas Gerais. ${ }^{5}$ Estas investigaciones constituyen la base de la reflexión sobre las cuestiones expuestas en los párrafos precedentes, así como sobre la naturaleza propia de las ciudades en lo que concierne a las posibilidades de realización del derecho a la ciudad. Porque de eso se trata fundamentalmente: cuestionar cuál el sentido de la vida en la ciudad hoy día y qué rol desempeńa en el desarrollo de la sociedad.

Para intentar dar respuesta a tales cuestiones, en este artículo se destacan, de la amplitud metodológica a la que se recurrió en las investigaciones citadas, las

3 De ese modo, para Baudrillard (2009), el consumo ya no puede ser entendido solo como posesión o práctica funcional de los objetos ni tampoco como propiciador de prestigio individual o de grupo, porque actualmente representa un lenguaje desde el cual establecemos las relaciones de sociabilidad.

4 Ciudades investigadas en el ámbito del proyecto de investigación "Lógicas económicas y prácticas espaciales contemporáneas: ciudades intermedias y consumo”, apoyado por la Fundação de Amparo à Pesquisa do Estado de São Paulo (fapesp), Brasil.

5 Ciudades investigadas en el ámbito del proyecto de investigación "Urbanización y fragmentación socioespacial en contextos no metropolitanos", apoyado por el Conselho Nacional de Desenvolvimento Científico e Tecnológico (cNpq), Brasil. 
observaciones realizadas en los trabajos de campo y el conjunto de entrevistas ${ }^{6}$ hechas a ciudadanos de distintos grupos de edad, condiciones socioeconómicas, niveles educacionales y residentes en distintas zonas de las ciudades mencionadas. ${ }^{7}$ Atención especial reciben las cuestiones referentes a los cambios en la ciudad y en el consumo familiar.

El punto de partida de esta indagación es la consideración del consumo como una categoría de análisis vasta, polisémica y difusa, relativa a la satisfacción de las necesidades de las personas y grupos sociales, y que abarca desde las necesidades primarias hasta las más complejas, englobando el consumo de bienes culturales y simbólicos, así como el uso y apropiación del espacio. Tal enfoque de la noción de consumo contempla esa diversidad de sentidos, aunque el análisis que aquí se plantea se asienta en el significado del acceso a determinados tipos de bienes, productos y espacios, por parte de los grupos socioeconómicos que solo recientemente han sido integrados en el mercado consumidor. En ese sentido, consumos banales (chocolate, carne, gaseosas, paseo durante los fines de semana, etcétera) son considerados como medios de integración a la sociedad de consumo, puesto que quien no consume tiende a ser invisibilizado. En este marco, se enfatiza el potencial que el acceso al consumo puede tener como empoderamiento de los sujetos en la construcción de sus identidades, condición necesaria para que se vean como alguien que tiene derecho a tener derechos.

\section{Del derecho a la ciudad en la sociedad de consumo}

Henri Lefebvre desarrolla la noción de derecho a la ciudad al mismo tiempo en que aparecen las formulaciones respecto de la sociedad de consumo, hechas tanto por él mismo en varias de sus obras (cf. Lefebvre, 1971, 1976, 1978, 1983, 1999, 2000), como por otros (cf. especialmente Baudrillard, 1969, 1981, 2009, y más recientemente Bauman, 2007, 2010).

En el pensamiento de Lefebvre, la lucha por el derecho a la ciudad aparece de modo claro como alternativa anticapitalista, en cuanto se asienta en la revaloración del uso por sobre el cambio, en una ciudad no solo cada vez más sometida a los intereses del mercado, sino también utilizada como medio para el desarrollo de la acumulación de capital. Así, es del propio autor (1973b) la tesis según la cual el capitalismo sobrevive a través de la producción del espacio.

6 Se hicieron 88 entrevistas entre los años 2012 y 2015 en las ciudades mencionadas. Diferentes investigadores del equipo del proyecto se dedicaron a este trabajo, siguiendo un guion de cuestiones predefinido y abordando los siguientes temas: perfil personal, productos adquiridos, frecuencia y locales de adquisición, medios de locomoción, modos de pago, cambios y perspectivas de consumo.

7 Aunque el análisis de las entrevistas haya sido fundamental para el desarrollo de las ideas presentadas en este artículo, ellas no aparecen exhaustivamente citadas en el texto, en función de nuestra preocupación por la construcción teórica; vale decir, nos interesa más en este momento la comprensión de los procesos generales que el abordaje de las especificidades empíricas propias de cada ciudad. Además, la limitación del número de páginas es igualmente un aspecto que no hemos podido ignorar. 
"Las ciudades no vendrían a ser más que unidades de consumo correlativas de las grandes unidades de producción”, afirma Lefebvre (1973a, p. 32), para situarlas en el ámbito del rol que pasan a desempeñar dentro de una sociedad capitalista posindustrial. Es decir, una sociedad que ha incorporado la industria como elemento banal de su desarrollo económico y ahora avanza hacia el cruce entre el consumo de masas como centro de las relaciones de sociabilidad, y las inversiones financieras hechas por los grandes grupos económicos en diversos sectores del consumo, como el inmobiliario, el comercio mayorista y minorista, el ocio y el entretenimiento. Baudrillard (2009) refuerza esa comprensión de la ciudad como expresión de la sociedad de consumo cuando afirma que:

La ciudad es el lugar geométrico de esta escalada, de esta "reacción en cadena" diferencial, que sanciona la dictadura total de la moda. (Ahora bien, el proceso refuerza a su vez la concentración urbana, por la aculturación rápida de las zonas rurales o marginales. Por lo tanto, es irreversible. Toda veleidad de bloquearlo es ingenua). La densidad humana en sí es fascinante, pero sobre todo, el discurso de la ciudad es la competencia misma: móviles, deseos, encuentros, estímulos, el veredicto incesante de los otros, erotización continua, información, solicitación publicitaria son todos elementos que componen una suerte de destino abstracto de participación colectiva, sobre un fondo real de competencia generalizada. (pp. 61-62, destacados en el original)

De modo paralelo, trabajamos con la tesis de que, en el ámbito de la urbanización contemporánea, la fragmentación socioespacial se ha desarrollado como tendencia que expresa tanto las rupturas de la continuidad territorial y de la compacidad del ambiente construido (Cataláo, 2013), como un conjunto de prácticas de apropiación selectivas y segmentadas (Catalão, 2013; Magrini, 2013), lo que denota una ciudad en pérdida de organicidad (Prévôt-Schapira, 1999).

El debate sobre la fragmentación vuelve complejo el análisis de los procesos de diferenciación socioespacial, a medida que considera los contenidos de la segregación y los amplía para incluir tres dimensiones indisociables: la producción del tejido urbano, la realización de las prácticas espaciales y la constitución de los imaginarios urbanos (Magrini, 2013).

Desde el punto de vista de los tejidos, tenemos, por un lado, la expansión de la ciudad vinculada a lógicas que separan los diferentes tipos de hábitat; y por otro, los emprendimientos comerciales, industriales y de servicios en estructuras espaciales desconectadas, caracterizadas por espacios públicos limitados a vías de circulación. No obstante, la fragmentación del tejido urbano no se restringe a las áreas de expansión. En la estructura urbana más consolidada se identifican enclaves socioespaciales de dos tipos principales: uno relacionado con las estrategias de clausura que producen áreas residenciales o emprendimientos inmobiliarios cerrados, vigilados y de acceso controlado - como centros comerciales y barrios/condominios cerradospara los grupos socioeconómicos de más alto poder adquisitivo; otro vinculado a las estrategias de evitación que generan agrupamientos de viviendas no físicamente cerrados, pero simbólicamente aislados, como favelas y asentamientos populares segregados. 
Los ciudadanos, en sus prácticas espaciales, no se apropian de la ciudad en su integralidad, pues los enclaves citados cercenan sus posibilidades de apropiación y contribuyen a crear imaginarios urbanos disyuntivos; es decir, la ciudad no es vista ya como un conjunto orgánico, sino como una variedad de fragmentos con los cuales, en gran parte, no se establecen relaciones de identidad o pertenencia. Las prácticas de los ciudadanos están cada vez más vinculadas al consumo del/en el espacio, a contramano de relaciones de compartición, apropiación y disfrute urbanos.

Los imaginarios urbanos, que son las construcciones simbólicas que nortean la vida en la ciudad, terminan por obstaculizar la comprensión del derecho a la ciudad como posibilidad, porque están marcados por la ideología del consumo como meta principal de las experiencias urbanas.

Según Prévôt-Schapira (1999), por lo tanto:

La fragmentation résulte de la disparition du fonctionnement global au profit de petites unités, la dilution des liens organiques entre les morceaux de la ville, l'appauvrissement du continuum spatial et la répétition des inégalités aux différentes échelles infra-urbaines, des îlots de pauvreté jouxtant des isolats de richesse au sein des archipels urbains. (p. 129)

Harvey (2013), al discutir el rol de la urbanización en el proceso de acumulación capitalista y sus movimientos de contestación, llega a una conclusión sobre la necesidad de que el derecho a la ciudad sea puesto como reivindicación de la lucha anticapitalista. Al respecto se pregunta, en determinado momento de su obra, si los movimientos urbanos que han ocurrido en diversas partes del mundo solo tienen la ciudad como locus de su manifestación, o si es ella la que fundamentalmente impulsa su existencia. Es precisamente este punto el que se propone desarrollar este artículo, pero recolocándolo del siguiente modo: ¿qué rol cumplen las ciudades en la reproducción de las relaciones de injusticia y perpetuación de las desigualdades?; $y$ ¿es posible encontrar en las ciudades las condiciones mismas para la ruptura de esas relaciones?

Soja (2008) advierte sobre la importancia de "poner las ciudades primero", lo que significa dos premisas complementarias.

En primer lugar, se trata de reconocer el peso que han tenido las ciudades en el desarrollo de la humanidad. Esto implica tener en cuenta que han sido ellas las instancias motivadoras de los principales avances tecnológicos, incluidas su propia invención hace cerca de diez mil años; las innovaciones en la agricultura y la crianza de animales, desde la primera revolución agrícola que produjo el excedente necesario a la perduración de las ciudades; la invención de la rueda y la escritura, y la revolución industrial hasta llegar a la revolución tecnológica, que implantó las bases para la mundialización de lo urbano (Soja \& Kanai, 2007) e hizo del campo parte constitutiva del proceso de urbanización.

A partir de lo anterior, en segundo lugar, "poner las ciudades primero" constituye un manifiesto por la valoración de la ciudad como elemento mediador de las relaciones y condición para las transformaciones necesarias a la superación de las contradicciones generadas por el actual modo de producción y, por consiguiente, para el combate a las injusticias y desigualdades socioespaciales. 
Lo que aquí se propone, por lo tanto, se inscribe en esa perspectiva; esto es, en una visión de la ciudad como producto de un contexto de desigualdades estructurales generadas por el proceso de acumulación capitalista y de una tendencia a la instalación de prácticas fragmentarias vinculadas al desarrollo de la sociedad de consumo. Tal proceso, señalamos, tiene como expresión la pérdida de unidad funcional de la ciudad (Salgueiro, 1997); y en él, el logro del derecho a la ciudad aparece como único camino posible para recuperar los sentidos más amplios de la ciudadanía, vinculados a su origen urbano, esto es, en tanto pertenencia a la ciudad.

Se habla mucho del derecho a la salud, del derecho al espacio, del derecho a la belleza, del derecho a las vacaciones, del derecho al saber, del derecho a la cultura. (...) Todo esto (...) tiene un sentido ambiguo y puede leerse en cierto modo en el sentido inverso: sólo hay derecho al espacio a partir del momento en que ya no hay espacio para todos y a partir del momento en que el espacio y el silencio son privilegio de algunos a expensas de los otros. (Baudrillard, 2009, p. 51, destacados en el original)

Con ello en vista, presentamos la contradicción dialéctica como elemento analítico que posibilita avanzar desde la crítica al consumo como alienación, en tanto factor de primer orden tras la desigualdad y la fragmentación socioespacial, a su valoración como elemento que posibilita la construcción de la ciudadanía, elemento imprescindible de la lucha por el derecho a la ciudad. La contradicción se presenta, pues, como camino para su propia superación, lo que lleva a valorar el consumo como dimensión constitutiva de la ciudadanía contemporánea - porque hay "dimensôes de cidadania que passam pelo mercado, assim como existe uma dimensão política no consumo" (Taschner, 2010, p. 48)-y situar el debate en los términos siguientes:

FIGURA I Contradicción dialéctica entre el consumo y el derecho a la ciudad

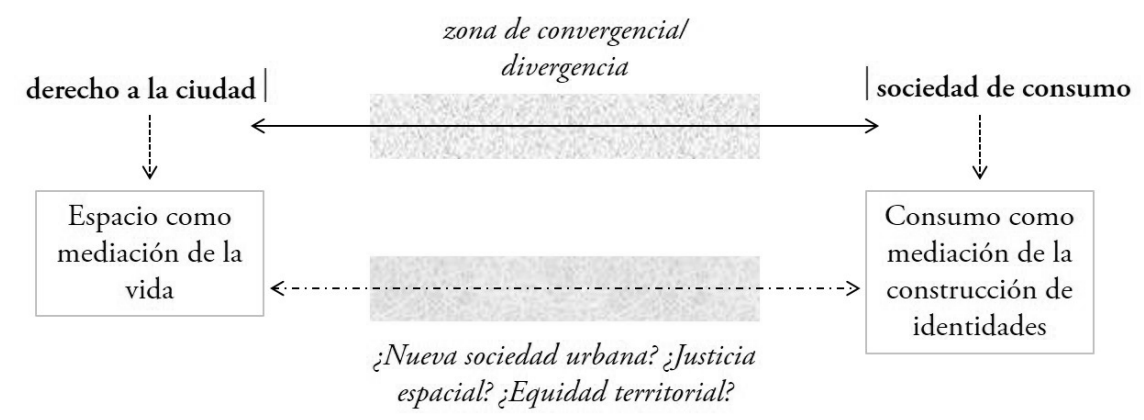

FUENTE ELABORACIÓN PROPIA

Considerando que en la sociedad de consumo la valoración del espacio ocurre principalmente como valoración capitalista de la tierra urbana, en un estudio anterior (Cataláo \& Magrini, 2016) defendimos la idea de que la realización plena del derecho a la ciudad se situaría en oposición al punto ocupado por el consumo, lo que podría llevar, de cierta manera, a abandonar la defensa de ese derecho como algo que se sitúe en el plano de lo posible, una "u-topía" (Lefebvre, 1999). Es decir, 
si el derecho a la ciudad es algo que solo se realizaría en una sociedad no capitalista o poscapitalista, no habría razones para defenderlo en esta sociedad, teniendo en vista que la esperada revolución proletaria, en los términos puestos por Marx y Engels (2000), no solamente no ocurrió, sino que parece no tener posibilidades de ocurrir. ${ }^{8}$

Harvey (2013) ayuda a superar esa coyuntura reflexiva cuando propone que las luchas por el derecho a la ciudad, expresadas en los diferentes movimientos de contestación de varios países del mundo -desde la proclamación de la Comuna de París, en 1871, hasta las insurrecciones más recientes, como las jornadas de junio de 2013 en Brasil-, están resituando la propuesta de revolución en otro nivel. Se trata así de reconocer el "estímulo a la aglomeración urbana" como elemento integrador fundamental para el desarrollo de la ciudad a lo largo de la historia, y también como germen transformador y liberador inherente a las ciudades, que Soja (2008) denomina "sinecismo": "El sinecismo connota las interdependencias económicas y ecológicas y las sinergias creativas, así como también destructivas, que surgen del agrupamiento intencionado y de la cohabitación colectiva de la gente en el espacio" (p. 42).

Además, aunque hayamos contemplado la posibilidad de convergencia entre el derecho a la ciudad y la sociedad de consumo, no habíamos indicado de qué manera eso sería posible. Ello se resuelve, por lo menos parcialmente, con los aspectos apuntados en los párrafos anteriores, que llevan a entender que es necesario considerar la sociedad de consumo como sociedad urbana; por lo tanto, como expresión del desarrollo histórico de la ciudad y de lo urbano, una sinergia destructiva que contiene las potencialidades para hacerse creativa. Esto nos obliga a considerar el rol del consumo como mediación en la construcción de las identidades individuales y colectivas; luego, como algo que no puede ser descartado en el debate sobre la justicia y la equidad socioespaciales contemporáneas. El derecho a la ciudad debe ser así representado de manera que contemple los cambios societarios, en especial el rol que el consumo desempeña en la integración y la sociabilidad de los grupos socioeconómicos más pobres.

\section{Consumo y ciudadanía: contradicciones y convergencias}

La problemática central tratada en este artículo está anclada en la contradicción dialéctica identificada en la relación entre derecho a la ciudad y consumo. De una parte, el consumo se ha constituido como antítesis del derecho a la ciudad (Cataláo \& Magrini, 2016), en el sentido de que las decisiones de los agentes económicos sobre dónde implantar sus negocios y las prácticas espaciales de los citadinos, ambas combinadas, tienden a reforzar el proceso de fragmentación socioespacial, incluso en ciudades intermedias. De otra parte, en la sociedad de consumo, este representa un medio de integración e identidad social, abriendo nuevas posibilidades para comprender dimensiones como la ciudadanía y la política y reponiendo la cuestión de la justicia espacial en otros términos. 
La contradicción mencionada se expresa en la convergencia de dos planos de análisis en conflicto: el plano teórico, "ideal"; y el plano de la vida cuotidiana, el de la experiencia urbana. En el primero se da la reconocida inadmisibilidad del derecho al consumo como sustituto del derecho a la ciudad, lo que suscita la necesidad de un análisis crítico de la centralidad del consumo como motor de la disminución de las desigualdades. En el segundo plano se constata la imposibilidad de dejar de lado el consumo, puesto que es, en la actualidad, la expresión general de los cambios, una mediación socioespacial importante, especialmente para los grupos que tenían poder de compra muy precario y que solo recientemente han logrado acceder al consumo.

En esta perspectiva, el consumo debe ser entendido como una dimensión alienante, desmovilizadora y privatista, a la vez que puede ser igualmente integradora, contestataria y potencialmente revolucionaria. Nuestra hipótesis se construye a partir de la constatación de que el proyecto anticapitalista que garantizará el derecho a la ciudad, entendido como derecho a la producción y participación de la vida urbana cuotidiana (Harvey, 2013), no puede prescindir del intento de recalificar y reposicionar las prácticas socioespaciales, entre las cuales se incluyen las prácticas de consumo. El derecho a la ciudad solo puede alcanzarse ampliamente si cuestionamos los preceptos que estructuran la sociedad capitalista, o sea, si ponemos en discusión las contradicciones entre la defensa incondicional del derecho a la propiedad privada a despecho de la función social de la propiedad urbana y de la ciudad; la producción del espacio urbano para la obtención de plusvalía a partir de la superposición del valor de cambio sobre el valor de uso; las lógicas de sociabilidad cuotidianas pautadas en la privatización y el rechazo de las dimensiones colectivas de la vida. Esos son ejemplos de aspectos que deben necesariamente componer el proyecto anticapitalista del que estamos hablando, acompañando Lefebvre (1999) y Harvey (2013).

Al respecto, considerar que la ampliación del acceso al consumo resuelve el problema del derecho a la ciudad constituye una simplificación de la cuestión urbana, que luego puede llevar a un error generador de ideas reformistas y reaccionarias. No obstante, no es posible ignorar que el consumo es condición indispensable para que puedan delinearse ideales revolucionarios, puesto que en la sociedad y las ciudades contemporáneas el consumo es mediador de las distintas dimensiones de la vida.

Harvey (2013) subraya que no es una tarea fácil distinguir las iniciativas reformistas de las revolucionarias en el contexto urbano, ya que, a lo largo de su implantación, incluso ellas pueden experimentar transformaciones de su carácter. Así, una iniciativa que parece tener amplitud limitada puede desarrollar líneas más radicales, al igual que una idea revolucionaria puede, en la práctica, revelarse conservadora. De ese modo, no parece factible considerar que una revolución urbana pueda ser puesta en marcha sin contradicciones y movimientos de avance y retroceso. Harvey (2013) ejemplifica esa cuestión cuando afirma:

Del mismo modo que Marx calificó las restricciones a la duración de la jornada de trabajo como una primera etapa en una vía revolucionaria, reivindicar el derecho de todos a vivir en un domicilio y un entorno de vida decentes puede verse como una primera etapa hacia un movimiento revolucionario más general. (p. 201) 
De esta forma, si consideramos que, en el panorama de la sociedad de consumo vigente, la posibilidad de acceder a la vivienda, por ejemplo, ocurre de modo más inmediato como consumo, no podemos posicionarnos contrarios a las iniciativas que buscan garantizar viviendas populares con subsidios o facilidades de crédito, aunque ello esté lejos de significar que no debamos ser críticos de esas iniciativas ni, menos aún, que debamos sentirnos plenamente satisfechos con ellas.

Poniéndolo de otra forma, en un contexto en el que grandes segmentos de la población no logran acceder a la vivienda, productos y servicios básicos porque están precariamente insertados en la sociedad de consumo, no parece inadecuado defender la integración de esas personas al consumo para que puedan vivir de manera más justa y digna. El peligro está en contentarse con eso o creer que el acceso al consumo puede por sí solo garantizar la reducción de las desigualdades socioespaciales.

Reforzamos el hecho de que no es posible esperar que aquellos que se han visto expoliados de la vida urbana (Kowarick, 1993), hoy fuertemente impregnada por el consumo, puedan tener parte en la construcción revolucionaria del derecho a la ciudad. Para ello, es necesario que se reconozcan y sean reconocidos como integrantes de la vida urbana, como parte de la sociedad y como agentes que comparten los espacios urbanos. Según afirma Harvey (2013), el derecho a la ciudad es un significante vacío que solo adquiere sentido en la construcción compartida de la vida urbana y de los espacios urbanos, que contienen en sí una multiplicidad de prácticas alternativas posibles. De ese modo, el autor destaca que el derecho a la ciudad no puede ser tratado como derecho a la ciudad capitalista tal como la conocemos. El derecho a la ciudad solo puede ser considerado en el porvenir del proceso de urbanización.

(...) el derecho a la ciudad tiene que plantearse, no como un derecho a lo que ya existe, sino como un derecho a reconstruir y recrear la ciudad como un cuerpo político socialista con una imagen totalmente diferente, que erradique la pobreza y la desigualdad social y que cure las heridas de la desastrosa degradación medioambiental. Para que esto suceda habrá que interrumpir la producción de las formas destructivas de urbanización que facilitan la perpetua acumulación de capital. (Harvey, 2013, p. 202)

En ese sentido, la pregunta que sirve como telón de fondo para nuestras reflexiones es la siguiente: si la efectivación del derecho a la ciudad pasa por la construcción de movimientos sociales progresistas que busquen revolucionar la vida urbana cuotidiana, ¿cómo es posible pensar en concientización y movilización social si parte de los residentes de las ciudades no se ven ni son vistos como integrantes de la sociedad, como seres con derecho a tener derechos?

Es en ese contexto que se hace necesario rescatar la dimensión política del consumo, considerando que el hecho de consumir no es una práctica solo individual, dirigida únicamente a satisfacer necesidades y deseos personales. Consumir, en el ámbito de la sociedad de consumo, es también el hecho de posicionarse, de marcar posiciones sociales y subvertir jerarquías, que debe ser probado también por los segmentos más pobres, aunque reconozcamos que existen limitaciones en la 
práctica política del consumo que necesitan ser superadas. Para Mansvelt (2008), "there still seems to be less emphasis on the significance and experience of collectively consumed objects and services, and on struggles over the nature and governance of collective consumption" (p. 106).

Sobre ese aspecto, encontramos en el trabajo de Borges Almeida (2015) un caso emblemático de cómo el acceso al consumo puede significar integración social, aumento de la autoestima, construcción de identidad y reconducción de la trayectoria de vida. El trabajo de la autora tiene como objetivo presentar la historia de mujeres de distintas condiciones sociales, para construir una biografía impregnada por sus testimonios. La historia que nos llamó la atención es la de Zélia, 54 años, residente en la ciudad de Urberlândia, Minas Gerais. Zélia ha tenido una vida sufrida. Fue rechazada por su madre, humillada y golpada por su primer marido, estigmatizada por haberse divorciado, y tuvo que trabajar desde temprano para criar sola a sus tres hijas. Su último trabajo fue en reparación de neumáticos, el que tuvo que dejar por recomendación médica tras sufrir un tercer accidente vascular cerebral. Vive de la renta de jubilado de su actual marido y de servicios de bordado que hace en casa para una industria de calzados.

La cuestión del consumo aparece en la historia de Zélia como un contrapunto a todas las dificultades por las que ha pasado en su vida. Un primer aspecto que destacamos es cómo la posibilidad de frecuentar ciertos espacios de consumo -aunque no sea para efectivamente consumir algo, sino como experiencia del espacio en sí- actúa en la construcción de su identidad: se siente moderna y un ser humano cuando va a tiendas y supermercados.

Não precisa comprar nada não, só ficar olhando (...). Eu ando lá dentro [do supermercado] e chego a ficar doidinha com as coisas. É bonito demais aquilo ali. Nossa! Eu acho lindo! Eu acho que, para uma mulher se_sentir moderna, ela tem que pôr uma roupa boa e ir para o mercado (...). Toda vez que nós recebemos, nós vamos lá e compramos uma roupinha. ${ }^{9}$ (Borges Almeida, 2015, pp. 32-34, destacado nuestro)

Eu me sinto gente na Telha Norte, no Bretas, no Extra, nas Casas Bahia, na Leroy. Eu não conhecia. Eu morei mais de dez anos em Uberlândia e eu vim conhecer esses "trem" depois que eu fechei a borracharia. ${ }^{10}$ (Borges Almeida, 2015, pp. 32-34, destacado nuestro)

No hace falta comprar nada, solo mirar (...). Yo camino allá dentro [del supermercado] y me pongo loquita con las cosas. Es muy bonito aquello todo. ¡Vaya! ¡Lo encuentro lindo! A mí me parece que, para que una mujer se sienta moderna, ella tiene que ponerse una buena ropa e irse al supermercado (...). Todos los días de cobro, vamos allá y nos compramos una ropita. [Traducción libre del testimonio debido a la informalidad del discurso, que puede dificultar la comprensión a los hispanohablantes].

10 Yo me siento gente en la [tienda] Tella Norte, en el [supermercado] Bretas, en la [tienda] Casas Bahia, en la [tienda] Leroy [Merlin]. Yo no las conocía. Yo he vivido más de diez años en Uberlândia y solo he logrado conocer esas cosas cuando dejé el trabajo de reparación de neumáticos. [Traducción libre del testimonio]. 
Esos fragmentos revelan cómo nuestras reflexiones acerca del consumo necesitan aproximarse al cuotidiano de los residentes urbanos de distintos grupos socioeconómicos, desde sus prácticas hasta sus representaciones. Lo que puede parecer un acto banal para muchos, como ir al supermercado, puede significar una actividad especial para otros que, hasta hace poco tiempo, no habían accedido a ese tipo de espacios: es un momento considerado tan especial que se espera todo el mes por él y para el cual se pone una "buena ropa".

Cuando alguien como Zélia dice "sentirse gente" en los momentos en que concurre a un espacio de consumo, se hace evidente la necesidad de resituar y ampliar nuestra perspectiva en relación con el consumo. Para ciudadanos como ella, los puntos de vista críticos de autores como Lefebvre (1971, 1999), Baudrillard (2009), Bourdieu (1998) y Featherstone (2000), entre otros, aunque sean fundamentales y un importante punto de partida, se muestran insuficientes. Es innegable que la centralidad del consumo en la sociedad contemporánea debe ser cuestionada, porque tiene un carácter desmovilizador, sirve como dimensión de distinción social manejada por los segmentos más ricos, está basada en la alienación -sostenida por el fetiche y la reificación de la mercancía- y actúa como elemento de exclusión social. Cuando prescinde de una solidaridad colectiva, el consumo puede ser considerado como un catalizador para la desintegración social y la fragmentación socioespacial, porque sustituye la dimensión del ser/estar por la del tener/(a)parecer. Mientras tanto, defendemos la idea de que esas críticas sirven para las prácticas de consumo realizadas por los segmentos socioeconómicos medios y para las elites, esto es, los que pueden elegir, los que participan efectivamente de la sociedad de consumo.

Nos preguntamos, por otro lado, sobre la situación de los que malamente viven bajo la lógica mercantil capitalista que sostiene la sociedad de consumo, compartiendo sus ambiciones, valores y símbolos, pero sin contar con las condiciones financieras necesarias para realizar las prácticas de consumo que hoy sirven de mediación de la vida urbana. Tales grupos se quedan doblemente marginados, si consideramos la inseparabilidad de las dimensiones materiales y subjetivas del acto de consumir. No consiguen acceso a las mercancías, servicios y espacios capaces de proporcionarles materialmente una vida digna y justa, y además no pueden manejar simbólicamente el consumo en la producción de representaciones e identidades fundamentales en el cuotidiano urbano. Para esos ciudadanos, ¿no puede el acceso al consumo significar el comienzo de la construcción de una experiencia urbana ciudadana?

Ejemplificamos mejor nuestra argumentación acerca de las ponderaciones necesarias al análisis de las prácticas de consumo urbano con fragmentos de tres entrevistas hechas en las ciudades de São José do Rio Preto, Londrina e Ituiutaba. Cuando son cuestionados sobre las transformaciones de los últimos diez años en relación con la capacidad de consumo de sus familias, los entrevistados destacan el acceso a ciertos bienes y productos que antes no componían el conjunto de mercancías consumidas frecuentemente.

Bom, para mim [ter uma casa] era um sonho. (...) minha mãe, até hoje, não conseguiu a casa dela, ela sempre fez inscrição. E eu na época, quando casei, no meu 
primeiro casamento, ainda estava grávida do meu filho. Meu filho tinha doze anos, praticamente, quando aconteceu de sair a casa, ia fazer doze anos e eu fiquei todo esse tempo esperando, entáo para mim era um sonho. (...) Posso dizer que deu uma melhorada, porque na época, era tudo bem apertado; depois que veio a casa, a prestação é bem menor em vista do aluguel, foi onde abriu um espaço. (...) Um pastel, nem que seja uma vez por mês, um sorvete de final de semana, refrigerante para acompanhar o almoço e a janta. (...) Chocolate para as crianças, doce. (...) porque eram coisas que não tinha como comprar. [...] Colocar piso na casa, aumentar a casa, moto. ${ }^{11}$ (Vanessa y Cássio - Entrevista hecha en São José do Rio Preto, São Paulo, septiembre de 2014)

Mas eu acho que (...), comparando o poder de compra dos meus pais antigamente com agora, a situação está bem melhor. Sem dúvida. Minhas tias também, as irmãs do meu pai, minha avó... tem mais regalia. Dá para comprar várias... comer uma pizza no final de semana, (...) sair, fazer alguma coisinha, mesmo que seja modesta (...). Acho que está bem melhor. (...) Alimentos; tem certas coisas que em casa eu não tinha. (...) Carne todo dia, às vezes não tinha (...). Carro (...) estar com um melhor; reforma em casa. ${ }^{12}$ (Ingridi - Entrevista hecha en Londrina, Paraná, febrero de 2014)

Em vista do que eu vivi, isso aqui está bom demais da conta. É muito importante. Para bem dizer, é um recomeço. Porque quando eu morava lá na outra casa eu náo saía do lugar, eu ficava parada no tempo. Não tinha condição de comprar uma casa, o aluguel era caro demais, então a gente não tinha perspectiva. (...) No bairro, precisa colocar os bueiros, porque nas esquinas não tem. Precisa de um ponto de policiamento mais perto, regularizar o posto de saúde (...). Tem que duplicar a pista ali embaixo, pois a gente que vem de coletivo corre o risco de ser atropelada (...) Eu acho que, como eles deram essa opção do Minha Casa Melhor, eles tinham que dar uma condição para a gente adquirir uma condução com preço e juros mais baixos, porque não é fácil, não é sempre que tenho dois, quatro reais para pagar

11 Bueno, para mí [tener una casa] era un sueño. (...) mi mamá hasta hoy día no ha logrado tener una casa, aunque siempre se haya inscrito [en los programas de vivienda popular]. Yo cuando me casé, en mi primer matrimonio, todavía estaba embarazada de mi hijo. Él tenía casi doce ańos cuando tuvimos acceso a la casa. Él iba ya a cumplir doce años, que es el tiempo que pasé esperando, así que era para mí un sueńo. (...) Puedo decir que ha mejorado mucho porque, en aquella época, todo era bastante difícil. Después que tuvimos la casa, la prestación es más pequeña si la comparamos al alquiler, o sea que hubo un espacio [en el presupuesto]. (...) Una croqueta, aunque sea una vez al mes, un helado el fin de semana, una gaseosa para acompañar el almuerzo o la cena. (...) Chocolate para los niños, un dulce. (...) porque eran cosas que no podíamos comprar. (...) poner un suelo en la casa, aumentarla, comprarse una moto. [Traducción libre del testimonio; no se utilizaron los nombres verdaderos, para preservar la identidad de las personas].

12 A mí me parece que (...), si comparo el poder de compra de mis padres antiguamente con la situación actual, está bien mejor, sin duda. Mis tías también, las hermanas de mi padre, mi abuela... hay más ventajas. Se pueden comprar varias cosas... comer una pizza en el fin de semana, (...) salir, hacer algo fuera, aunque sea algo modesto (...). Creo que está bien mejor. (...) Alimentos, hay cosas que en casa yo no tenía. (...). Carne todo el día a veces no había (...). Coche (...) ahora tenemos uno mejor, reformamos la casa. [Traducción libre del testimonio]. 
um ônibus. Eu não tenho como vir aqui na hora do almoço, porque se eu tiver que pegar o coletivo, eu fico no meio do caminho. ${ }^{13}$ (Camila - Entrevista hecha en Ituiutaba, Minas Gerais, noviembre de 2014)

Entre los productos mencionados por los entrevistados, el acceso a la vivienda o al automóvil son los que transforman de modo más directo sus vidas, permitiendo otras relaciones con la ciudad. No obstante, también es enormemente significativa para los segmentos más pobres la ampliación del consumo de algunos alimentos. Mientras, para algunos, el consumo de carne, chocolate y refrescos, por ejemplo, es bastante habitual, para otros tiene distintos significados: novedad, conquista, mejora de vida. Si, para algunos, comer pizza y tomar un helado el fin de semana es una práctica banal, para otros representa nueva forma de ocio familiar que era impensable antes de las posibilidades de ampliación del consumo.

La entrevista de Camila demuestra especialmente la contradicción que estamos enfatizando; es decir, de una parte, las nuevas posibilidades de acceso al consumo vinculadas a la adquisición de un inmueble; y, de otra, el reconocimiento de las limitaciones de ese acceso y de las necesidades todavía no satisfechas, lo que abre perspectivas reivindicatorias vinculadas a la pertenencia a la sociedad de consumo, otrora inexistentes. También aclara una especificidad brasileña, porque en este país el desarrollo de una sociedad de consumo no se ha visto acompañado de la presencia del Estado como proveedor de los bienes y servicios públicos, lo que ha reforzado históricamente tanto la inclusión de segmentos socioeconómicos más ricos, como el alejamiento y la subordinación de los segmentos más pobres. Por último, también revela la tenuidad de los límites entre la alienación y la liberación inherentes al consumo, puesto que, según Camila, resolver los problemas relacionados con las ausencias del Estado significa en gran medida tener nuevas formas de consumo. Debemos, por lo tanto, producir una politización del acceso al consumo, en lugar de limitarnos a descartarlo como algo que simplemente debe ser despreciado.

En la línea que se ha planteado, en una sociedad en la que el consumo se realiza de manera muy desigual entre los diferentes segmentos socioeconómicos, no se puede desechar la potencia transformadora del acceso al consumo para los segmentos más pobres. Para ellos, la ampliación de tal acceso puede representar una inclusión más ciudadana en la sociedad y en el contexto urbano en que viven. Puesto de otro modo, ¿podemos hablar de ciudadanía y de una ciudad más justa sin contemplar el acceso a la vivienda, la circulación y la salud, de un lado, y sin contemplar el

13 Comparando con lo que he vivido, eso está demasiado bueno. Es muy importante, es decir, es un recomienzo. Porque cuando yo vivía en la otra casa, yo no salía del lugar, me quedaba parada en el tiempo. No tenía condiciones para comprarme una casa, el alquiler era demasiado alto, entonces no teníamos perspectiva. (...) [Mientras tanto] en el barrio se necesita poner más drenajes para las aguas de lluvias, porque en las esquinas no hay. Se necesita un puesto de policía más cerca, fijar el centro de salud (...). Hay que ampliar la vía de acceso allí abajo, porque nosotros que cogemos autobuses corremos el riesgo de ser atropellados (...). Yo pienso que como nos han dado la opción del Mi Casa Mejor [programa de ayuda a la reparación y el equipaje del hogar], debían darnos la condición para adquirir un automóvil con precio e interés más bajos, porque no es fácil, no es siempre que tengo dos o cuatro reales [entre 50 céntimos y 1 dólar aproximadamente] para pagar el billete de autobús. No puedo venir a casa para almorzar, porque si tengo que coger el autobús me quedo en el medio del camino. [Traducción libre del testimonio]. 
consumo de alimentos diversificados, ropas y zapatos, muebles, electrodomésticos y actividades de diversión y entretenimiento, de otro?

Esas reflexiones nos llevan a recalificar la comprensión del significado de la ciudadanía en la sociedad contemporánea, puesto que consideramos que ella es un presupuesto indisociable de la búsqueda del derecho a la ciudad. Sobre ese aspecto, Taschner $(2009,2010)$ presenta una perspectiva sumamente innovadora para la comprensión de la relación entre consumo y ciudadanía, aunque no la haya desarrollado de manera suficiente. Según la autora, gran parte de los análisis tratan el consumo y la ciudadanía como campos distintos. Sin embargo, cuando se los piensa de manera conjunta, se enfatizan las relaciones de oposición y de exclusión mutua. Lo que ella propone es la comprensión multifacética, no siempre polarizada, de las relaciones entre ciudadanía y consumo. De ese modo, si bien reconoce ciertos límites del consumo como propiciador de ciudadanía, también entiende que debemos estar atentos a comprender otras relaciones posibles.

Assim, é possível haver (e certamente há) consumidores absorvidos pela cultura de consumo e pela indústria cultural e de entretenimento que a sustenta que, tal como afirmam Adorno e Horkheimer (1973), não conseguem perceber a realidade além do que ela tem de aparente, de imediatamente visível. Também faz sentido a preocupação de Bauman (2001) com a falta de participação social organizada dos cidadãos e com prejuízo que ela traz para a democracia, fato que o autor vê ligado a um comportamento consumista. Não se deve tampouco desconsiderar a colocação de Sennett (2006) em relaçâo a cidadãos contemporâneos que tomam decisões e fazem escolhas políticas segundo a mesma lógica que preside suas escolhas de consumo: agem como se estivessem comprando produtos de uma determinada marca. Mas esses fatos não devem ser assumidos como universais, pois o impacto da cultura do consumo não é homogêneo na sociedade. Além disso, não esgotam o espectro de relaçōes existentes ou possiveis entre a cultura de consumo e a cidadania hoje. (Taschner, 2010, p. 49, destacados nuestros)

Los análisis de la autora se dirigen hacia las acciones de los movimientos sociales de defensa del consumidor. Así, Tascher (2010) entiende que hay una "relação clara e consistente, de reforço mútuo, entre consumo e cidadania” (p. 51), mediada por las reivindicaciones y conquistas de derechos para los consumidores, que hacen las relaciones de consumo menos abusivas. Nos parece que la idea de la autora puede extrapolarse al análisis de la complejidad de relaciones entre consumo y ciudadanía en las ciudades, y ello a partir del reconocimiento del consumo como ejercicio político e integración social, capaz, por lo tanto, de establecer un frente de tensión de la propia sociedad de consumo vigente, y haciendo así posible vislumbrar un nuevo orden urbano.

Para avanzar en nuestras proposiciones, es necesario abordar la ciudadanía y el consumo desde una perspectiva más amplia, que considere las características de la sociedad contemporánea. Las contribuciones de García Canclini (1995) indican que la relación entre los términos "consumidores" y "ciudadanos" ha cambiado en todo el mundo a partir de las transformaciones producidas en las esferas económica, tecnológica y cultural, que organizan las identidades según nuevas lógicas, 
no exclusivamente desde referentes simbólicos nacionales. Esas ideas refuerzan la comprensión del desarrollo de una sociedad de consumo, como ya hemos tratado.

Para el autor, las relaciones estrechas entre consumo y ciudadanía pueden ser tratadas como pérdida y despolitización en relación con los ideales de democracia liberal o iluminista. Mientras tanto, nos advierte que debemos considerar que la dimensión política de la ciudadanía se amplía si incluimos los derechos de vivienda, salud y educación y el acceso a otros bienes mediante el consumo. Desde esa proposición, en su "Prefácio à edição inglesa" de Consumidores e cidadãos (2006), García Canclini subraya la necesidad de conceptuar el consumo, pasando a tratarlo "não como simples cenário de gastos inúteis e impulsos irracionais, mas como espaço [sic] que serve para pensar, e no qual se organiza grande parte da racionalidade econômica, sociopolítica e psicológica nas sociedades" (p. 14). Además, el autor contribuye para la ampliación del entendimiento de la ciudadanía más allá de su contenido jurídico-político cuando afirma que:

(...) ser ciudadano no tiene que ver sólo con los derechos reconocidos por los aparatos estatales a quienes nacieron en un territorio, sino también con las prácticas sociales y culturales que dan sentido de pertenencia y hacen sentir diferentes a quienes poseen una misma lengua, semejantes formas de organizarse y satisfacer sus necesidades. (García Canclini, 1995, p. 19)

Se trata, por tanto, de otra comprensión de ciudadanía, que ratifica lo que presenta Voyce (2006) en los siguientes términos:

By citizenship I do not mean a person's right, as a member of the state where 'membership' is given or claimed through belonging to a national territory. Rather, citizenship is seen as 'a set of practices (juridical, political economic and cultural) which define a person as competent member of society and which as a consequence define the flow of resources to a person' (Turner, 1993). Public space/citizenship notions are converging into one discourse, that shopping areas are reserved for shoppers only and that consumption is the basis of citizenship. This new form of identity is not linked to the idea of belonging to a particular place, but is based upon the ability to buy consumer goods. (p. 282)

La construcción de la ciudadanía se ve traspasada, así, por la construcción de representaciones de pertenencia e identidad. Sobre este aspecto, Bauman (2005) afirma que los procesos de identificación son igualmente poderosos elementos de estratificación, puesto que en nuestra sociedad las identidades sociales necesitan ser construidas, lo que generalmente es hecho por el mercado, ya que ellas no son tan solo el resultado de lazos heredados de contextos familiares o de nacionalidad, por ejemplo. De ese modo, las desigualdades presentes en los distintos niveles de integración al consumo tienen consecuencias directas en las posibilidades de producción de las identidades sociales.

Bauman (2005) destaca incluso que, en uno de los polos de la jerarquía social, están los que pueden construir y desarticular sus identidades de la manera y en el momento que eligen, o sea, los que tienen poder adquisitivo suficiente para elegir y consumir los símbolos de su identidad. En el otro polo están los que no pueden 
elegir, y menos aún construir sus identidades, y que se quedan, por tanto, a la merced de identidades impuestas por otros: "Identidades de las que se resienten pero de las que no se les permite despojarse y que no consiguen quitarse de encima. Identidades que estereotipan, que humllan, que deshumanizan y que estigmatizan" (Bauman, 2005, p. 86). En una posición intermedia está gran parte de la sociedad, la que consigue manejar sus identidades sin nunca saber el tiempo que durará su libertad de elegir lo que desea o rechazar lo que le desagrada.

En ese sentido, se ratifica la hipótesis de que la dimensión del consumo no puede ser descartada cuando tratamos de la producción de identidades que modelan la ciudadanía. Por ende, no hay posibilidad de construcción del derecho a la ciudad si partes de la población continúan alejadas del consumo que les garantizaría el reconocimiento de un rol, incluso en la construcción de ideales y prácticas urbanas bajo la perspectiva revolucionaria. Sobre ese aspecto, García Canclini (1995) refuerza el carácter procesual de la construcción de la ciudadanía.

(...) más que como valores abstractos, los derechos importan como algo que se construye y cambia en relación con prácticas y discursos. La ciudadanía y los derechos no hablan únicamente de la estructura formal de una sociedad; además, indican el estado de la lucha por el reconocimiento de los otros como sujetos de "intereses válidos, valores pertinentes y demandas legítimas". (p. 20)

Reafirmamos también el carácter procesual de la construcción del derecho a la ciudad, que ocurre en el ámbito de disputas y embates por el derecho a participar, de múltiples maneras, en la producción de la vida y de los espacios urbanos. Pretendemos, pues, mover el centro analítico desde las perspectivas que reconocen la aniquilación o el agotamiento de las bases revolucionarias de la sociedad -en los términos de Bauman (2005), por ejemplo, que contrapone la sociedad de productores de la época moderna y su solidaridad de clase a la sociedad de consumidores contemporánea, caracterizada por la individualidad, el privatismo y luego la fragmentación de identidades de consumidores incapaces de poner en pauta alternativas revolucionarias-, hacia la comprensión de que necesitamos resituar las cuestiones y aspiraciones revolucionarias en el centro de la sociedad de consumo, observando sus especificidades.

Nos apoyamos en la proposición de Harvey (2013), quien, al tratar las potencialidades de rebeldía e insurgencia inherentes a las ciudades, afirma que es en la vida cuotidiana que se encuentran "los espacios de esperanza claves para la construcción de un tipo de globalización alternativo y una política decidida contra la mercantilización de todo, en la que las fuerzas progresistas de la producción y la trasformación cultural puedan tratar de apropiarse y socavar las fuerzas del capital” (p. 167). Añadimos a esta proposición la comprensión de que el consumo puede ser una de esas dimensiones privilegiadas para la subversión de ciertas lógicas mercantiles de la producción de las ciudades al sustituirlas por lógicas más justas e igualitarias, porque estamos de acuerdo con García Canclini (1995) cuando afirma que:

(...) cuando se reconoce que al consumir también se piensa, se elige y reelabora el sentido social hay que analizar cómo interviene esta área de apropiación de bienes y signos en formas más activas de participación que las que habitualmente se ubican 
bajo el rótulo de consumo. En otros términos, debemos preguntarnos si al consumir no estamos haciendo algo que sustenta, nutre y hasta cierto punto constituye un nuevo modo de ser ciudadanos. (p. 27)

\section{Conclusiones}

A lo largo de este artículo, hemos hecho el esfuerzo de situar el debate sobre el consumo en el ámbito de la inexorabilidad del desarrollo de una sociedad (urbana) de consumo (Lefebvre, 1999), que tiene la práctica de dicha actividad como elemento fundamental de su sociabilidad. Ello ubica la reflexión sobre el derecho a la ciudad en otros términos. Pensamos que es fundamental redefinir los elementos necesarios para la realización de ese derecho a partir de una nueva conceptualización -aunque sea embrionaria- de aquello que hoy parece contrario a su existencia, como es la extensión inclusiva del consumo. Puesto de otra manera, no es posible pensar el derecho a la ciudad como nostalgia de una ciudad que ya no existe, expresión a la vez de una sociedad que igualmente dejó de existir.

En ese sentido, sin todavía conseguir avanzar hacia proposiciones intervencionistas, concluimos el texto presentando algunas formulaciones que pueden apuntar hacia la construcción de una teoría sobre el derecho a la ciudad y el derecho al consumo que los comprenda de manera complementaria, en el sentido de hacer del consumo, que es inherente a la vida urbana contemporánea, una "sinergia creativa", porque él se realiza en el ámbito de los vínculos colectivos que aún sostienen la existencia de las ciudades y son el motor del desarrollo societario humano (Soja, 2008).

Voyce (2006) analiza la ineluctable producción de lo que llama "nuevos espacios públicos" y "espacios semipúblicos", es decir, superposiciones de inversiones capitalistas - como los centros comerciales- y formas de apropiación comunitaria del espacio. Al hacerlo, llama la atención hacia el rol que desempeńa el consumo en la vida cuotidiana, considerando los comportamientos creados y las normas establecidas a partir de la convivencia y del contacto en los distintos espacios de consumo, especialmente por la clase media.

Moreover the group of shoppers thus formed, through their social capital (etiquette, habits, outlooks), project their norms in the sense that the space becomes a 'political' norm through what has been called the 'spatialization of virtue' (Osborne and Rose, 1999). This 'virtue' links the particular form of architecture and security with the view of the middle-class righteousness of the new public space. This 'virtue' of space thus both reinforces and establishes proper behaviour for the new public space. (Voyce, 2006, p. 281)

A partir de ello, transponiendo el análisis a los segmentos socioeconómicos menos favorecidos, nos preguntamos si también para ellos no rige la norma política espacial y el capital social originarios de las prácticas y la convivencia en los espacios de consumo, en los términos puestos por Voyce (2006), que indicarían un nuevo comportamiento urbano.

Nos parece que es este el camino indicado por Santos (2004) cuando analiza las potencialidades técnicas para la construcción de otra mundialización en el ámbito 
de un período popular de la historia; vale decir, la simple inclusión en la sociedad de consumo quizá no representa per se la superación de la condición desigual que la sociedad capitalista impone, pero puede ofrecer las condiciones desencadenantes del proceso revolucionario.

No obstante, tenemos conciencia de los límites de ese enfoque, que podría llevarnos al error de una teoría quimérica sobre el potencial del consumo, en la misma dirección que alerta el propio Santos (2004) respecto de la mundialización como fábula. Aún nos resta, por lo tanto, apuntar algunas indagaciones que no podremos desarrollar en este artículo.

Primero, ¿cómo esta norma espacial, instituida en términos de comportamientos, hábitos y prácticas en los espacios de consumo de que trata Voyce (2006), podría ser utilizada como punto de partida de la transformación de una ciudad restrictiva para el cambio, en una ciudad inclusiva para el uso?

Segundo, continuando la cuestión anterior, si el consumo es uno de los elementos propiciadores de la fragmentación socioespacial que pulveriza las ciudades en un conjunto heterogéneo y disyuntivo de prácticas y espacios, ¿cómo puede también cumplir el rol de elemento integrador?

Tercero, ¿qué posibilidades, por ende, pueden avizorarse para la vida urbana futura en términos de reducción de las desigualdades socioespaciales, considerando los potenciales de la relación entre consumo y vida urbana?

Provisoriamente, lo que podemos afirmar es que la respuesta a esas cuestiones pasa necesariamente por la valoración de la propia ciudad como elemento central de cualquier proceso revolucionario, tal como ha ocurrido desde su origen hasta los días actuales.

En ese sentido, por último, nos preguntamos también si serían las ciudades intermedias, en función de sus intensas relaciones de proximidad y favorecidas por la más pequeña escala de los eventos, las que son más adecuadas al desarrollo de los potenciales transformadores que estamos enfatizando. Contestar a esa cuestión no es tarea fácil y requiere profundización teórico-metodológica que nosotros, tal como otros investigadores, estamos buscando enfrentar.

\section{Agradecimientos}

Nos gustaría agradecer al CNPq y la FAPESP por los financiamientos que hacen posibles las investigaciones. Agradecemos, de igual modo, a los colegas que han leído nuestro texto y presentado sugestiones, correcciones y contribuciones. No podemos, lamentablemente, citarlos a todos aquí. Muy especialmente, agradecemos a Juliana Catalão, Sergio Moreno Redón y revista EURE por su ayuda con la revisión de la lengua española. 


\section{Referencias bibliográficas}

Bartelt, D. D. (Ed.) (2013). A "nova classe média" no brasil como conceito e projeto político. Río de Janeiro: Fundação Heinrich Böll.

Baudrillard, J. (1969[1968]). El sistema de los objetos. México, D.F.: Siglo xxi.

Baudrillard, J. (1981). Simulacres et simulation. París: Galilée.

Baudrillard, J. (2009[1971]). La sociedad de consumo: sus mitos, sus estructuras. Madrid: Siglo XXI.

Bauman, Z. (2005). Identidad. Madrid: Losada.

Bauman, Z. (2007). Vida de consumo. México, D.F.: Fondo de Cultura Económica.

Bauman, Z. (2010). Mundo consumo: ética del individuo en la aldea global. México, D.F.: Paidós.

Borges Almeida, D. (2015). Memórias de mulheres: perfis biográficos de femininos múltiplos. Tesis de Maestría en Tecnologías, Comunicación y Educación. Universidade Federal de Uberlândia.

Bourdieu, P. (1998). La distinción: criterio y bases sociales del gusto. Madrid: Taurus.

Brenner, N. \& Schmid, C. (2015). Towards a new epistemology of the urban? City, 19(2-3), 151-182. https:// doi.org/10.1080/13604813.2015.1014712

Catalão, I. (2013). Différence, dispersion et fragmentation socio-spatiale: explorations métropolitaines à Brasilia et Curitiba. Tesis de Doctorado en Geografía. Université d'Avignon et des Pays de Vaucluse/Universidade Estadual Paulista, Presidente Prudente.

Catalâo, I. \& Magrini, M. A. (2016). Can consumption mediate the right to the (fragmented) city? Brazilian Geographical Journal: Geosciences and Humanities research medium, 7(1), 19-32.

Featherstone, M. (2000). Cultura del consumo y postmodernismo. Madrid: Amorrortu Editores.

García Canclini, N. (1995). Consumidores y ciudadanos. Conflictos multiculturales de la globalización. México, D.F.: Grijalbo. En http://bit.ly/2m3MQ5D]

García Canclini, N. (2006). Consumidores e cidadãos. Conflitos multiculturais da globalização. $6^{a}$ Ed. Río de Janeiro: Editora UfrJ.

García Canclini, N. (2010). Cidades rebeldes: do direito à cidade à revolução urbana. São Paulo: Martins Fontes.

Guiddens, A. (2002). Modernidade e identidade. Río de Janeiro: Jorge Zahar Editor.

Harvey, D. (2013). Ciudades rebeldes. Del derecho de la ciudad a la revolución urbana. Traducción de Juanmari Madariaga. Madrid: Akai. En http://bit.ly/KTgRkl]

Kowarick, L. (1993). A espoliação urbana. $2^{a}$ Ed. Río de Janeiro: Paz e Terra.

Lefebvre, H. (1971). Everyday life in the modern world. Nueva York: Harper \& Row Publishers.

Lefebvre, H. (1973a). Espacio y politica: el derecho a la ciudad II. Barcelona: Península.

Lefebvre, H. (1973b). La survie du capitalisme: la re-production des rapports de production. París: Anthropos.

Lefebvre, H. (1976). Espacio y política. Barcelona: Península.

Lefebvre, H. (1978). El derecho a la ciudad. $4^{\mathrm{a}}$ Ed. Barcelona: Península.

Lefebvre, H. (1983). La presencia y la ausencia: contribución a la teoría de las representaciones. México, D.F.: Fondo de Cultura Económica.

Lefebvre, H. (1999). A revolução urbana. Belo Horizonte: Editora Universidade Federal de Minas Gerais (UFMG).

Lefebvre, H. (2000). La production de l'espace. $4^{\mathrm{a}}$ Ed. París: Anthropos. 
Maffesoli, M. (2004). El tiempo de las tribus: el declive del individualismo en las sociedades de masa. México, D.F.: Siglo XXI.

Magrini, M. A. (2013). Vidas em enclaves: imaginário das cidades inseguras e fragmentação socioespacial em contextos não metropolitanos. Tesis de Doctorado en Geografía, Universidade Estadual Paulista, Presidente Prudente. En http://repositorio.unesp.br/ handle/11449/105071?show=full

Mansvelt, J. (2008). Geographies of consumption: Citizenship, space and practice. Progress in Human Geography, 32(1), 105-117. https://doi.10.1177/0309132507080623

Marx, K. \& Engels, F. (2000[1848]). Manifiesto comunista. Toronto: elaleph.com.

Osorio, J. (2004). El Estado en el centro de la mundialización: la sociedad civil y el asunto del poder. México, D.F.: Fondo de Cultura Económica.

Peet, R. (1977). The development of radical geography in the United States. Progress in Human Geography, 1(2), 240-263.

Prévôt-Schapira, M.-F. (2000). América Latina, la ciudad fragmentada. Revista de Occidente, n. 230-231, 25-46.

Salgueiro, T. (1997). Lisboa, metrópole policêntrica e fragmentada. Finisterra, 32(63), 179190. En https://dialnet.unirioja.es/servlet/articulo?codigo $=2381166$

Santos, M. (2004). Por otra globalización: del pensamiento único a la consciencia universal. Bogotá: Convenio Andrés Bello.

Simmel, G. (1983). Sociabilidade - um exemplo de sociologia pura ou formal. En E. Moraes Filho (org.). Sociologia (pp. 165-181). São Paulo: Ática.

Soja, E. W. (2008). Postmetrópolis: estudios críticos sobre las ciudades y las regiones. Madrid: Traficantes de Sueños.

Soja, E. W. \& Kanai, M. (2007). The urbanization of the world. En R. Burdett \& D. Sudjic (eds.), The endless city: the urban age project by the London School of Economics and Deutsche Bank's Alfred Herrhausen Society (pp. 54-69). Londres/Nueva York: Phaidon Press.

Sposito, M. E. (2007). Cidades médias: reestruturação da cidade e reestruturação urbana. En M. E. Sposito (org.), Cidades médias: espaços em transição (pp. 233-253). São Paulo: Expressão Popular.

Taschner, G. (2009). Cultura, consumo e cidadania. Bauru: Editora da Universidade Sagrado Coração (Edusc).

Taschner, G. (2010). Cultura do consumo, cidadania e movimentos sociais. Ciências Sociais Unisinos, 46(1), 47-52. http://www.redalyc.org/articulo.oa?id=93820632007

Turra Neto, N. (2008). Múltiplas trajetórias juvenis em Guarapuava: territórios e redes de sociabilidade. Tesis de Doctorado en Geografía. Universidade Estadual Paulista, Presidente Prudente.

Vicente, E. (2013). Nova classe média: um delírio coletivo? En D. D. Bartelt (org.). A “nova classe média" no Brasil como conceito e projeto político (pp. 81-93). Río de Janeiro: Fundação Heinrich Böll.

Voyce, M. (2006). Shopping malls in Australia: The end of public space and the rise of 'consumerist citizenship'? Journal of Sociology, The Australian Sociological Association, 42(3), 269-286. https://doi.org/10.1177/1440783306066727 